H. Ax, W. Meier, Experimental investigation of the response of laminar premixed flames to equivalence ratio oscillations, Combustion and Flame Volume 167 (2016) 172-183.

The original publication is available at www.elsevier.com

http://dx.doi.org/10.1016/j.combustflame.2016.02.014 


\title{
Experimental Investigation of the Response of Laminar Premixed Flames to Equivalence Ratio Oscillations
}

\author{
Holger Ax*, Wolfgang Meier \\ German Aerospace Center (DLR), Institute of Combustion Technology, Pfaffenwaldring 38-40, \\ 70569 Stuttgart, Germany
}

\begin{abstract}
A detailed experimental analysis of laminar premixed methane/air flames subject to equivalence ratio oscillations is presented. The equivalence ratio of methane/ air flames was periodically modulated by the addition of methane into the stationary fuel/air flow of a lean premixed flame. The reaction of the flame as a function of amplitude and frequency of the modulation was investigated in a parametric study. The flames were operated at reduced pressure $(70 \mathrm{mbar})$ in order to increase the spatial resolution across and within the flame front and to approximate the time and length scales of the flame and the induced equivalence ratio oscillations in an order of magnitude of $10 \mathrm{~Hz}$. The detection and evaluation of $\mathrm{OH}^{*}$-chemiluminescence revealed the shape and position of the flame front. Onedimensional laser Raman scattering was applied in order to simultaneously and quantitatively determine the concentration profiles of the major species and the temperature along the symmetry axis of the flame. The results show that several interacting effects occur, which have different dependencies on the oscillation frequency: first, a "macroscopic" reaction of the flame arises from the variation of
\end{abstract}

\footnotetext{
*corresponding author

Email address: holger . ax@dlr.de (Holger Ax)
} 
the laminar flame speed and the flow velocity and, hence, its location. Second, the structure of the flame front is affected by the diffusional transport processes and the influence of the oscillation on the species concentrations. At low frequencies, the flame can follow the oscillations reaching temporarily quasi-steady states at the minimum and maximum fuel fraction levels. At sufficiently high frequencies, the flame tip location remains virtually unchanged. However, the species profiles across the flame front show a significant phase shift relatively to each other and cannot be described by steady states throughout the oscillation period.

Keywords: equivalence ratio oscillations, laser Raman scattering, laminar flames, reduced pressure

\section{Introduction}

Gas turbines have great potential to cope with the increasing requirements of high efficiency in combination with low emissions and high flexibility regarding both fuels and the operational range. A promising and proven combustion concept is the lean premixed combustion. However, the coupling of pressure pulsations and heat release may lead to self-sustained thermo-acoustic instabilities in the combustion chamber which can diminish the gas turbine's performance or even cause structural damages [1,2]. Equivalence ratio oscillations have been identified to play a key role in the thermo-acoustic feedback-loop. Caused by pressure pulsations due to altered inflow conditions they lead to heat release variations and, thus, significantly contribute to the sustainment of instabilities [3-6]. Equivalence ratio oscillations are therefore of particular interest of the gas turbine manufacturers and the scientific community and have been studied in numerous investigations, both experimentally and theoretically. In most studies, equivalence 
ratio oscillations have been detected and investigated during and as part of thermoacoustic instabilities [4-10]. Only a few studies so far have focused on the effect of equivalence ratio oscillations on the flame behavior in particular.

Lieuwen and Zinn [3] and Sattelmayer [11] showed the importance of equivalence ratio oscillations by numerical investigations of their effect on the flame transfer function. The numerical model of Lieuwen was extended by Cho and Lieuwen $[12,13]$ in order to account for several effects of equivalence ratio oscillations on the heat release. A further extension of the model was published by Shreekrishna and Lieuwen [14] that included effects of flame stretch and nonlinear effects at higher oscillation amplitudes. Additionally, they investigated the response of the flame front structure to equivalence ratio oscillations at high frequencies with wavelengths of the disturbance in the same order of magnitude as the flame thickness. The findings indicated that beyond certain frequencies the flame front structures cannot be described by sequential steady states anymore due to the interaction and phase delay of convective and diffusional transport within the flame front. The limit frequencies for the non-quasi-steady behavior were given with $400 \mathrm{~Hz}$ at $1 \mathrm{~atm}$ and $4 \mathrm{kHz}$ at $10 \mathrm{~atm}$.

If this pressure dependency was extended to reduced pressure in order to approach the conditions that were investigated in the present study, a flame would become non-quasi-steady at $40 \mathrm{~Hz}$ at 100 mbar.

The effect of equivalence ratio oscillations on the lean blow out limit was numerically investigated on a methane/air stagnation flame [15], on a propane/air stagnation flame [16] and on a methane/air counter flow flame [17]. All studies revealed a quasi-steady flame behavior at low frequencies. However, at sufficiently high frequencies, i.e. if the gradients of the equivalence ratio variations were 
similar to the time and length scales of the flame, the flames continued burning at equivalence ratios in the fresh gas below the lean blow out limit of according steady flames due to the flame history. The heat and radicals that are produced in the reaction zone at locally higher equivalence ratios diffuse towards the fresh gas with locally lower equivalence ratios where they support the stabilization of the flame. Further numerical studies on equivalence ratio oscillations investigated the progression of oscillation amplitudes in the fresh gas and their effect on reaction kinetics [18], the impact on the heat release [19] or the effect of high amplitudes near the lean blow off limit [20].

The applied measurement techniques for the detection of equivalence ratio oscillations during thermo-acoustic instabilities include laser absorption spectroscopy $[6,9,10]$, chemiluminescence ratios [21-25] and laser-Raman scattering [5]. Equivalence ratio variations induced by external acoustic excitation have been experimentally investigated by Kang et al. [26] with planar laser-induced fluorescence (PLIF) on tracer particles and by Schwarz et al. [27] with both laserabsorption and Rayleigh scattering. However, quantitative analyses could not be done in both studies due to a low signal to noise ratio and a dominant effect of the induced acoustic pressure oscillations on the flame.

Another approach to investigate the effect of an inhomogeneous equivalence ratio distribution on laminar and weak turbulent flames was made by Sweeney and Barlow [28] on stratified flames that were generated by two adjacent slot burners with different equivalence ratios. Detailed multi-species and temperature profiles were obtained by the application of both Rayleigh and one-dimensional laser Raman scattering, laser-induced fluorescence (LIF) on $\mathrm{CO}$ and crossed $\mathrm{OH}$ PLIF. 
In a previous paper we described the experimental setup for the investigation of equivalence ratio oscillations by periodically added fuel [29]. This work and the works by Meier et al. [5] and Sweeney and Barlow [28] demonstrated the applicability of laser-Raman scattering in order to quantitatively investigate equivalence ratio oscillations with high spatial and temporal resolution. A unique advantage of laser-Raman scattering is the possibility to determine the temperature and the local mixture fraction by simultaneous multi-species measurements independent from the reaction progress of the combustion.

The present investigation focuses on the effects of equivalence ratio oscillations on the flame front by elimination or minimization of other effects. Flame phenomena of different time and length scales are considered in detail and related to one another. Experimental access to phenomena on small time and length scales was enabled by the operation of the flame at reduced pressure. The resulting broadening of the flame front has two useful effects for the experimental investigation: first, it allows spatially resolved measurements within the flame front and, second, it facilitates the approximation and overlap of the length scales of the flame thickness and the wavelength of the induced equivalence ratio oscillations.

In order to maximize the significance of the observations, other effects were eliminated as far as possible. By use of a perfectly premixed laminar flame, effects of unmixedness and flame/vortex interactions could be excluded. Flame/wall interactions were eliminated by use of a wide combustion chamber with a diameter eight times the diameter of the burner exit. Pressure pulsations were minimized by several means: the mass flow of the premixed flame was small compared to the total mass flow through the combustion chamber ( 20\%). An additional air mass flow convectively cooled the combustion chamber and damped pressure fluctua- 
tions from the flame. The outflow of the total mass flow was forced through the suction line (diameter $\sim 50 \mathrm{~mm}$, length $\sim 3 \mathrm{~m}$ ) of the low pressure pump. Thus, there was no typical bottle neck for a Helmholtz resonator.

Though the flame does not meet conditions that are relevant to technical applications, it provides a unique insight into the reactions of the flame front to equivalence ratio oscillations. Complementary optical and laser based techniques were applied in order to gain comprehensive results of the flame behavior and to avoid perturbations by sensor probes. The shape and position of the flame front were imaged by the detection of the $\mathrm{OH}^{*}$-chemiluminescence. The rotational symmetry of the flame allowed the deconvolution of the signal to a two-dimensional section through the flame.

A detailed characterization of the flame front structure was enabled by onedimensional laser Raman scattering. Simultaneously measured profiles of the major species and the temperature were determined along the symmetry axis from the burner exit to the exhaust gas region of the flame. This was done by imaging a section of $7 \mathrm{~mm}$ along the laser beam and a vertical translation of the burner. The capability of the chosen measurement techniques for a comprehensive investigation of the flame front has been demonstrated in Ax et. al [29].

The present paper deals with the measurements and the analysis of a parametric study on flames subject to equivalence ratio oscillations. The aim of the study was a detailed analysis of the flame front structure in dependence of the modulation frequency and amplitude. Of particular interest was the identification of unsteady effects at higher frequencies by approximation and overlap of the length scales of the oscillation and the flame front as they were predicted by several numerical simulations [14-17]. 
The results shall serve as a comprehensive data set for the validation of numerical simulation models since there are hardly any experimental data available under such special conditions.

\section{Experimental Setup}

The experimental setup is only briefly described here since a detailed description of the general setup has been given in [29] and [30]. Changes and improvements are mentioned which have been made for the parametric study that is presented here. All new information are given at the end of each paragraph. A schematic illustration of the setup is shown in Fig. 1.

A special burner configuration had been designed that enables the operation of stable and perfectly premixed Bunsen flames at reduced pressure as well as the variation of the equivalence ratio. The diameter of the burner exit was $40 \mathrm{~mm}$. The flames were stabilized by a surrounding flat flame, which was operated with a stoichiometric mixture of methane and oxygen [29]. The total mass flow of the stabilization flame was $1.79 \mathrm{~g} / \mathrm{min}$.

The equivalence ratio was varied by the pulsed addition of methane into the stationary premixed methane/air flow of a Bunsen flame through 48 tubes inside the burner with an exit diameter of $1 \mathrm{~mm}$ each. The pulsation was triggered by a magnetic 3/2-way valve (Staiger, model VA 304-715) that was located below the burner outside the combustion chamber [29]. The distance from the valve to the tubes' exit was around $250 \mathrm{~mm}$. The pull-in- and drop-out-times of the valve are not exactly known but well below $1 \mathrm{~ms}$. The opening and closing times could still be varied during operation tests of the valve at $500 \mathrm{~Hz}$. The effects of undefined flow and mixture conditions during opening and closing of the valve are therefore 


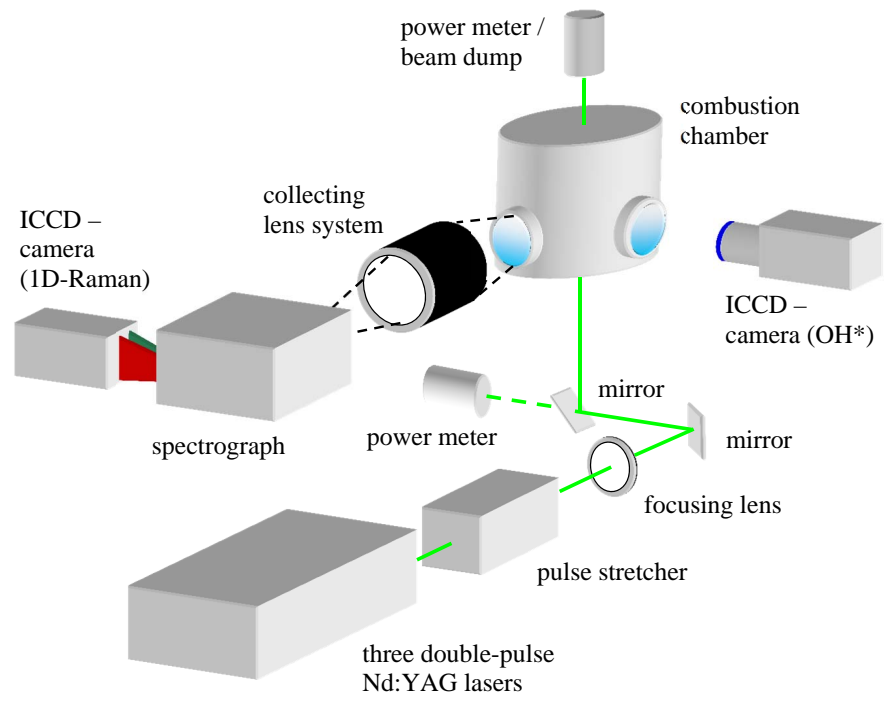

Figure 1: Schematic drawing of the experimental setup.

neglected. The tubes' exits were located $10 \mathrm{~mm}$ below the burner exit. This position was chosen based on an estimation during the design process in order to provide for a homogeneous fuel distribution in horizontal direction by diffusional transport within the distance to the burner exit. A thermocouple measured the fresh gas temperature at the same location.

The burner was pressure tight mounted into a combustion chamber with an inner diameter of $320 \mathrm{~mm}$ and a height of $318 \mathrm{~mm}$. A constant volume pump evacuated the combustion chamber through the exhaust gas pipe. The pressure inside the combustion chamber was measured by two sensor probes and automatically regulated by a software controlled orifice valve. The adjustable pressure range was defined by an additional air flow that entered the combustion chamber through a circular diffuser around the burner [29]. The mass flow was constantly set to $23.9 \mathrm{~g} / \mathrm{min}$ allowing an adjustable pressure range from 30 to $110 \mathrm{mbar}$. This co-flow also convectively cooled the combustion chamber wall. 
The mass flows for the Bunsen flame, the stabilization flame, the pulsed methane and the co-flow were separately controlled (Brooks 5850S and 5851S) and fed from pressurized gas bottles or in-house lines.

\section{1. $\mathrm{OH}^{*}$-Chemiluminescence}

The shape and position of the flame front were determined by the detection of the chemiluminescence of the electronically excited $\mathrm{OH}$ radical. Since $\mathrm{OH}^{*}$ is formed in the region of the highest heat release it is a good marker for the reaction zone $[31,32]$. All information of the experimental setup for the detection of the $\mathrm{OH}^{*}$-signal have been described in [29], only a short summary will be given here: The signal of the spontaneous emission of the $(\mathrm{A}-\mathrm{X})$ transition of $\mathrm{OH}^{*}$ around $310 \mathrm{~nm}$ was detected perpendicularly to the flame axis by an intensified CCD-camera equipped with a bandpass filter (314 nm $\pm 20 \mathrm{~nm}$ FWHM) as shown in Fig. 1. The gate width of $250 \mu$ s was still short compared to the observed effects as will be shown later. Due to the rotational symmetry of the flame, an Abel inversion could be applied in order to deconvolve the projection of a twodimensional section through the flame [33].

\subsection{Raman scattering}

For the laser Raman measurements, the beams of six frequency doubled Nd:YAG lasers ( $3 \times$ Spectra Physics PIV 400) were spatially overlaid, focused by a spherical lens with a focal length of $2 \mathrm{~m}$ and directed vertically through the combustion chamber and the burner along their central axis. A total energy of around $1.2 \mathrm{~J} /$ pulse with a repetition rate of $10 \mathrm{~Hz}$ was available at the measurement location. By means of a pulse stretcher and an appropriate trigger timing of the laser pulses, the laser energy was distributed over a pulse duration of about $350 \mathrm{~ns}$ in 
order to avoid optical breakdown at the focus. The laser energy of each pulse was measured before and after the combustion chamber by two power meters.

A section of $7 \mathrm{~mm}$ length along the laser beam was imaged by a customdesigned achromatic lens system (Linos, aperture $150 \mathrm{~mm}$ ), spectrally resolved by a spectrometer (Acton Research, SpectraPro 300i, 490 grooves $/ \mathrm{mm}$ ) and relayed onto the chip of an image intensified CCD-camera (Princeton Instruments PIMAX, Gen III intensifier, $1340 \times 700$ pixels used) with a magnification of 2 . The imaged spectral range of $163 \mathrm{~nm}$ covered the vibrational Stokes-Raman $(\Delta v=1)$ signal of the major species $\mathrm{CO}_{2}, \mathrm{O}_{2}, \mathrm{CO}, \mathrm{N}_{2}, \mathrm{CH}_{4}, \mathrm{H}_{2} \mathrm{O}$ and $\mathrm{H}_{2}$. The spatial resolution was given by the beam waist at the focus of around $400 \mu \mathrm{m}$ and a binning of the CCD pixels to 28 superpixels in the spatial dimension corresponding to a length of $0.25 \mathrm{~mm}$ each. The elastically scattered Rayleigh scattering and reflections from the combustion chamber walls were minimized by a holographic notch filter in front of the spectrograph.

All measured spectra were averaged over 300 single shots phase locked at specific phase angles of the equivalence ratio oscillations. The detected Raman signals were integrated over species specific spectral ranges and corrected for background luminosity, spectral overlap, laser intensity and a calibration factor that accounts for daily fluctuations of the signal intensity due to minor changes of the beam alignment or the optical imaging. The corrected signals $I_{c, i}$ were then evaluated in order to determine the species number densities $n_{i}$ based on a calibration data set by the relation $n_{i}=I_{c, i} /\left(I_{L} f_{i}(T) G_{i}(T)\right)$, with the calibration factor $G_{i}$, the laser pulse energy $I_{L}$ and the molecular Boltzmann population distribution $f_{i}$. The calibration data set had been established beforehand on electrically heated pure gases and in the equilibrium region of both $\mathrm{CH}_{4}$ /air and $\mathrm{H}_{2}$ /air flat flames. 
The signal calibration, reduction and evaluation are described in more detail in [29], [30] and [34].

The temperature evaluation was based on the ideal gas law using the total number density that was derived from the evaluated major species concentrations and the measured pressure inside the combustion chamber. The mixture fraction $f$ as proposed by Bilger [35] was used to express the ratio of fuel to air. The advantage of this definition is a constant value of the stoichiometric mixture fraction ( $f_{s t}=0.055$ for $\mathrm{CH}_{4}$ in air) in the occurrence of preferential diffusion.

The uncertainties of the deduced species concentrations, the temperature and the mixture fraction were estimated by use of the law of error propagation considering possible sources of systematic and statistical errors from mass flow controllers, laser power meters, pressure probes and calibration temperature measurements with thermocouples and coherent anti-Stokes Raman scattering (CARS) [29, 36-38]. Typical relative errors in the fresh gas region were 3.3\% for $\mathrm{N}_{2}, 4 \%$ for $\mathrm{O}_{2}, 3.8 \%$ for $\mathrm{CH}_{4}$ and $5 \%$ for the temperature. In the hot gas region, typical relative errors were $4.7 \%$ for $\mathrm{N}_{2}, 9 \%$ for $\mathrm{O}_{2}, 6.8 \%$ for $\mathrm{CO}_{2}, 5.4 \%$ for $\mathrm{H}_{2} \mathrm{O}, 7.2 \%$ for $\mathrm{H}_{2}, 17.4 \%$ for $\mathrm{CO}$ and $6.8 \%$ for the temperature.

\section{Results}

\subsection{Stationary Flame}

Prior to the findings that were obtained from the parametric study on equivalence ratio variations, the stationary reference flame without additional $\mathrm{CH}_{4}$ will be presented for a better understanding of the effects of equivalence ratio oscillations on that flame. The flame settings of the stationary flame were kept constant at a CH 4 mass flow of $\dot{m}_{C H 4}=0.217 \mathrm{~g} / \mathrm{min}$ and an air mass flow of $\dot{m}_{\text {air }}=5.56 \mathrm{~g} / \mathrm{min}$, 


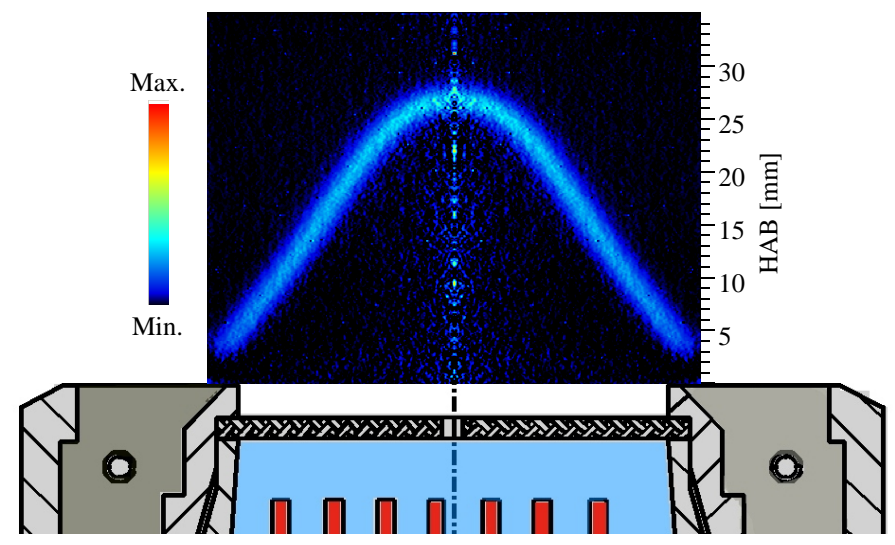

Figure 2: $\mathrm{OH}^{*}$-chemiluminescence of the stationary flame.

resulting in an equivalence ratio of $\Phi_{\text {stat }}=0.67$. The fresh gas at the burner exit reached the thermal equilibrium at around $315 \mathrm{~K}$ approximately 20 minutes after the ignition. All reported results were obtained at 70 mbar. The mean flow velocity at the burner exit was consequently $1.018 \mathrm{~m} / \mathrm{s}$.

Figure 2 shows a picture of the deconvolved $\mathrm{OH}^{*}$-chemiluminescence of the stationary flame. For a better impression of the dimension and position of the flame, a scale on the right and a schematic drawing of the burner exit at its actual position relatively to the flame are also shown. The flame has the typical shape of a Bunsen flame with nearly straight cone flanks. The $\mathrm{OH}^{*}$-signal is lifted from the burner by around $3 \mathrm{~mm}$ due to heat loss at the burner rim. The thickness of the $\mathrm{OH}^{*}$-signal normally to the flame surface is around $2 \mathrm{~mm}$, which indicates the widening of the flame front at reduced pressure. The dots with high signal intensity along the vertical central axis are artifacts from the Abel-inversion. The $\mathrm{OH}^{*}$-signal from the surrounding flat flame has been subtracted as an additional background luminosity.

The results of the 1D-Raman measurements along the central axis in this flame 


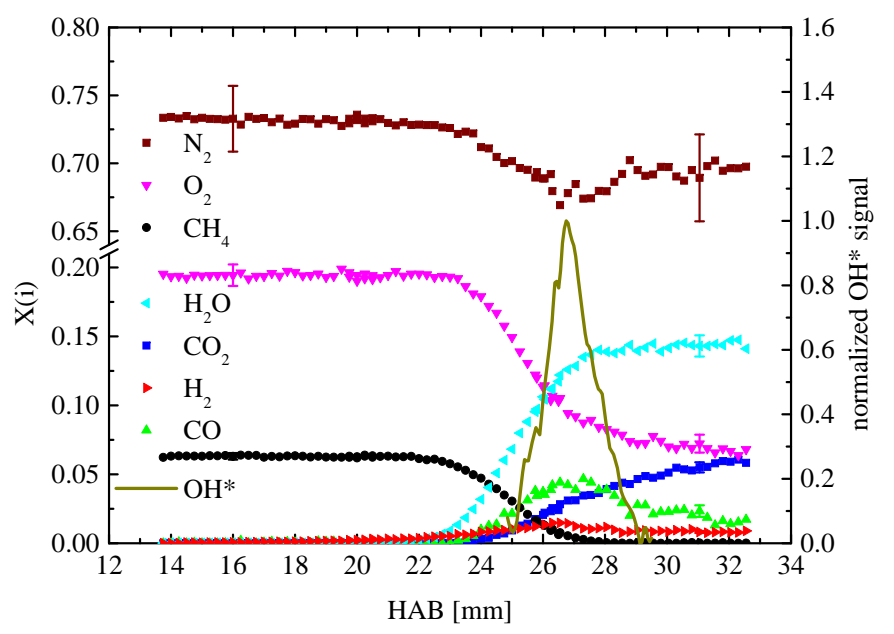

Figure 3: Species concentration profiles and $\mathrm{OH}^{*}$-chemiluminescence in a stationary flame.

are shown in Fig. 3. The profiles of the species concentrations are composed from measurements at three different heights above the burner on three different days, overlapping by about $1 \mathrm{~mm}$. One should note the discontinuity of the left scale that was inserted to show the concentration of all species in one graph. Additionally to the species concentrations, the profile of the $\mathrm{OH}^{*}$-signal along the central axis is also included in order to set the results of the two measurement techniques in a spatial relation. The $\mathrm{OH}^{*}$-signal intensity is normalized to its maximum since it is not evaluated quantitatively. The results are plotted from a height above the burner $(\mathrm{HAB})$ of $13.75 \mathrm{~mm}$ on; upstream, the concentrations and temperature are constant. For the sake of clarity, the error bars are plotted only once per species in both the fresh gas region and the hot gas region.

The profiles reveal the typical structure of a premixed flame front. In the fresh gas region up to a height of around $23 \mathrm{~mm}$, the concentrations of $\mathrm{CH}_{4}, \mathrm{O}_{2}$ and $\mathrm{N}_{2}$ are nearly constant. In the preheat zone, the concentrations decrease due to the diffusional transport to the reaction zone at around $27 \mathrm{~mm}$, where $\mathrm{CH}_{4}$ and 


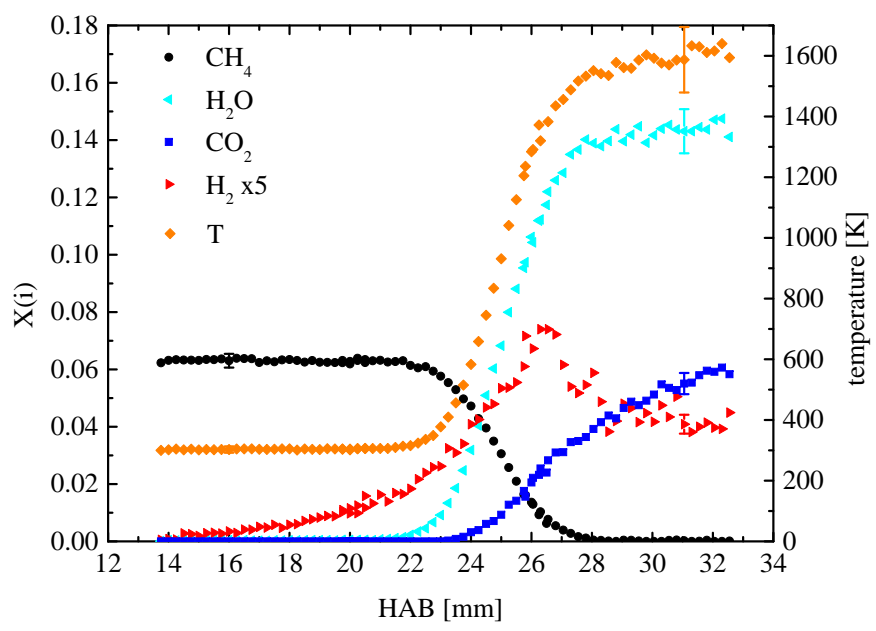

Figure 4: Selected species concentration and temperature across the flame front.

partly $\mathrm{O}_{2}$ are consumed. The reaction zone is marked by the peak of the $\mathrm{OH}^{*}$ signal. The maximum of the intermediate product $\mathrm{CO}$ is found close to the $\mathrm{OH}^{*}$ maximum. The maximum of the $\mathrm{H}_{2}$ concentration is about $1 \mathrm{~mm}$ upstream of the $\mathrm{OH}^{*}$ maximum. Subsequent to the reaction zone, the oxidation zone is clearly visible where slower combustion processes such as the oxidation of $\mathrm{CO}$ take place and the mixture slowly approaches the thermodynamic equilibrium. However, the measurements do not extent up to the thermodynamic equilibrium.

For a deeper insight into the flame front structure, some selected species concentration profiles $\left(\mathrm{CH}_{4}, \mathrm{H}_{2} \mathrm{O}, \mathrm{CO}_{2}\right.$ and $\left.\mathrm{H}_{2}\right)$ and the temperature are shown in Fig. 4. The $\mathrm{H}_{2}$-concentration is enhanced by a factor of five for a better visualization. The concentration of the product $\mathrm{CO}_{2}$ increases significantly later than the $\mathrm{H}_{2} \mathrm{O}$ concentration. The slope of $\mathrm{CO}_{2}$ also shows a different behavior compared to the profiles of $\mathrm{H}_{2} \mathrm{O}$ and the temperature. While the profiles of $\mathrm{H}_{2} \mathrm{O}$ and temperature increase strongly in the preheat zone and only slightly in the following oxidation zone, the increase rate of $\mathrm{CO}_{2}$ is similar in both zones. The profiles of 


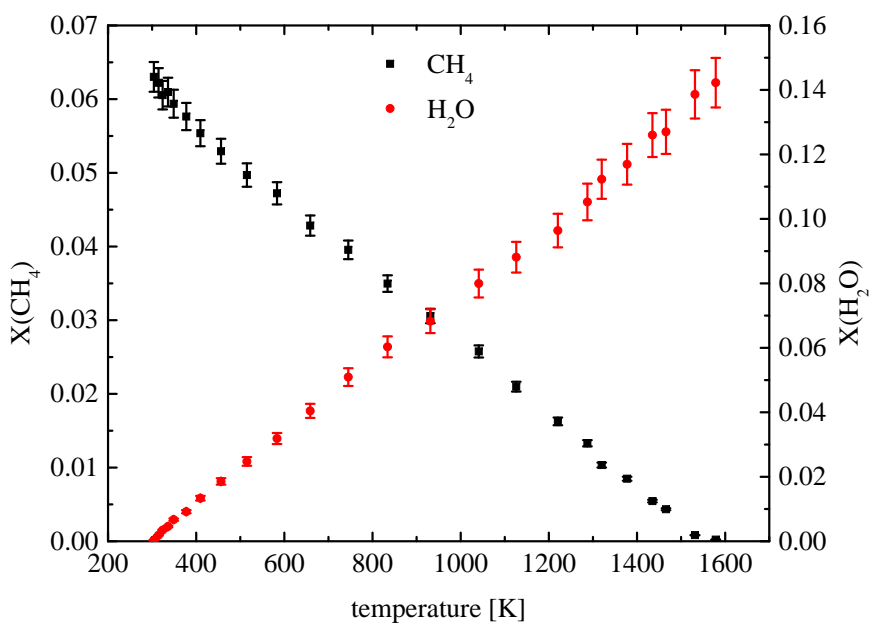

Figure 5: Correlation of $\mathrm{CH}_{4}$ and $\mathrm{H}_{2} \mathrm{O}$ with the temperature.

the $\mathrm{H}_{2} \mathrm{O}$ concentration and the temperature are rather congruent across the whole flame front if suitably scaled. The similarities of the profiles of $\mathrm{CH}_{4}, \mathrm{H}_{2} \mathrm{O}$ and the temperature become obvious when plotted against each other. The correlations of $\mathrm{CH}_{4}$ and $\mathrm{H}_{2} \mathrm{O}$ with the temperature are shown in Fig. 5. For the sake of clarity, the results were conditionally averaged in temperature steps of $10 \mathrm{~K}$ if applicable. The correlation of the species concentrations with the temperature is rather linear in both cases. This means, that the lengths of mass diffusion and thermal diffusion are similar and, hence, the Lewis-number $L e$, being the ratio of the diffusional length of the limiting species $\left(\mathrm{CH}_{4}\right)$ and the thermal diffusion length, is equal to $L e=1$ within the accuracy of the measurements.

The effects of preferential diffusion in the flame front become obvious in the case of $\mathrm{H}_{2}$ in Fig. 4. The diffusion coefficient of $\mathrm{H}_{2}$ is about three times higher than the diffusion coefficient of $\mathrm{CH}_{4}$ in air since $\mathrm{H}_{2}$ is much smaller and lighter than the other major species. The $\mathrm{H}_{2}$ concentration reaches its maximum of $1.5 \%$ at around $26 \mathrm{~mm}$ and decreases towards the preheat zone and the oxidation zone. 
In the imaged section of the oxidation zone, $\mathrm{H}_{2}$ can still be found in a significant amount of $0.8 \%$ at $\mathrm{HAB}=32.5 \mathrm{~mm}$. Upstream from the maximum, one can see that $\mathrm{H}_{2}$ diffuses far into the fresh gas region up to $\mathrm{HAB}=14 \mathrm{~mm}$.

The complex effects of preferential diffusion inside the flame front also lead to variations of the local fuel to air ratio. Figure 6 shows the mixture fraction across the flame front in dependence of the HAB. The results are averaged over two adjacent measurement volumes. One can see that the mixture fraction is almost constant in the fresh gas region. The values are close to the expected value of 0.0372 as deduced from the mass flows of air and fuel. With the beginning of the preheat zone, the mixture fraction decreases and reaches a minimum at around $\mathrm{HAB}=24 \mathrm{~mm}$. Subsequently, the mixture fraction increases until it reaches a rather constant level at around $\mathrm{HAB}=27 \mathrm{~mm}$, which is close to the maximum of the $\mathrm{OH}^{*}$-chemiluminescence. In the imaged section of the following oxidation layer, the mixture fraction remains on a level that is slightly higher than in the fresh gas due to effects of differential diffusion and minor species that could not be measured and quantified by Raman scattering. The results qualitatively agree well with the findings of Barlow et al. [39]. One should note that the indicated error bars in the fresh and hot gas region mark the absolute possible errors calculated by the law of error propagation. However, the relative error of the plotted samples is smaller which allows the analysis of the mixture fraction across the flame front.

\subsection{Oscillating flame}

The effects of equivalence ratio oscillations were investigated by the pulsed addition of $\mathrm{CH}_{4}$ to the previously presented stationary flame. The amount and frequency of the additional $\mathrm{CH}_{4}$ were varied in a parametric study. The variations are summarized in table 1 . For each frequency from $5 \mathrm{~Hz}$ to $40 \mathrm{~Hz}$, the additional 


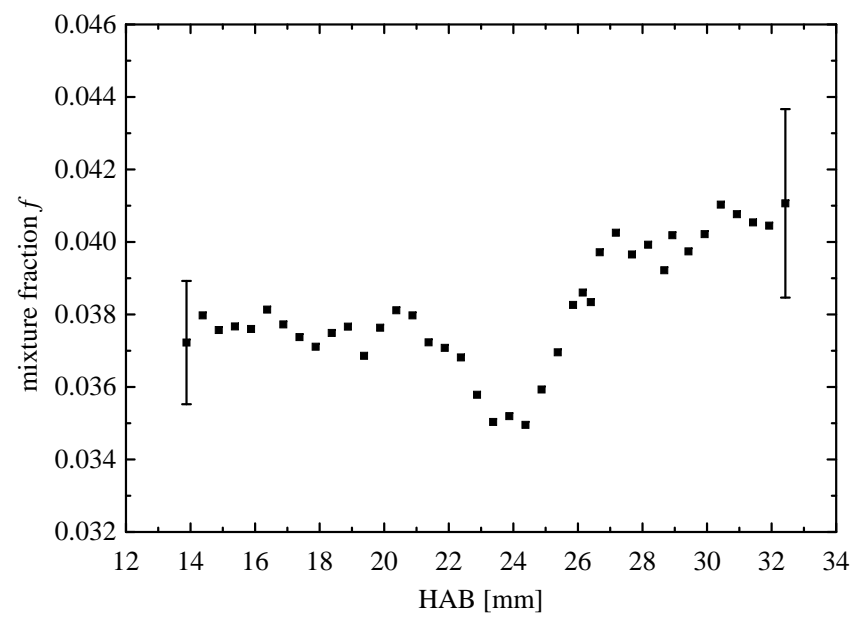

Figure 6: Mixture fraction across the flame front in dependence on the height above the burner.

$\mathrm{CH}_{4}$ was varied in three different amounts. The pulse strengths in table 1 are given relatively to the $\mathrm{CH}_{4}$ mass flow of the stationary flame. In the case of $50 \%$ additional $\mathrm{CH}_{4}$, the stoichiometric mixture is just reached. The opening time of the magnetic pulse valve was always set to the half period duration of the given frequency. While the valve was closed, the additional methane flow was bypassed into the outer region of the combustion chamber where it did not affect the flame. Thus, the pressure inside the additional fuel line was kept constant and the same as in the combustion chamber.

$\mathrm{OH}^{*}$-chemiluminescence and 1D-laser Raman measurements were taken at several phase angles of a period. At each phase angle, 300 single shot Raman measurements and $50 \mathrm{OH}^{*}$ images were taken and averaged for the evaluation. The time steps $\Delta t$ and according phase intervals $\Delta \varphi$ at the different frequencies are given in the column on the right hand side in table 1.

The homogeneous distribution of the additional methane in the stationary flow in horizontal direction was provided for by the 48 shower head like arranged tubes 


\begin{tabular}{c|c|c} 
frequency & pulse strength $\left(\frac{\dot{m}_{\mathrm{CH}_{4}, \text { puls }}}{\dot{m}_{\mathrm{CH}_{4}, \text { stat }}}\right)$ & $\Delta \mathrm{t} / \Delta \varphi$ \\
\hline $5 \mathrm{~Hz}$ & $10 \%, 25 \%, 50 \%$ & $10 \mathrm{~ms} / 18^{\circ}$ \\
\hline $10 \mathrm{~Hz}$ & $10 \%, 25 \%, 50 \%$ & $5 \mathrm{~ms} / 18^{\circ}$ \\
\hline $20 \mathrm{~Hz}$ & $10 \%, 25 \%, 50 \%$ & $2.5 \mathrm{~ms} / 18^{\circ}$ \\
\hline $30 \mathrm{~Hz}$ & $10 \%, 25 \%, 50 \%$ & $2 \mathrm{~ms} / 21.6^{\circ}$ \\
\hline $40 \mathrm{~Hz}$ & $10 \%, 25 \%, 50 \%$ & $2.5 \mathrm{~ms} / 36^{\circ}$
\end{tabular}

Table 1: Summary of parametric variations for the present study. See section 3.2 for explanations.

inside the burner and the effect of diffusional transport in horizontal direction. The distribution of the methane pulse in the surrounding main flow was investigated by 2D-laser-Raman scattering [29]. The results showed a homogeneous distribution within a few millimeters, which confirmed the assumption in the design process of a homogeneous methane distribution in horizontal direction by diffusional transport within the distance of $10 \mathrm{~mm}$ from the tubes' exit to the burner exit.

The effects of enhanced momentum and mass diffusion on the homogenization of the axial velocity profile and the mixture, respectively, at reduced pressure have also been shown by Ombrello and Carter [40] on a Hencken burner configuration at 125 Torr. Diffusional effects in the shear layer between the $\mathrm{CH}_{4} / \mathrm{O}_{2}$-flame were not investigated since the focus of this study was on the central flame axis in approximation of a one-dimensional flame.

\subsection{1. $5 \mathrm{~Hz},+25 \% \mathrm{CH}_{4}$}

Due to the limited space, only two representative flames out of the fifteen investigated flames will be discussed here in detail in order to show the effects and the underlying mechanisms. First, a flame with $25 \%$ additional $\mathrm{CH}_{4}$ at a frequency 


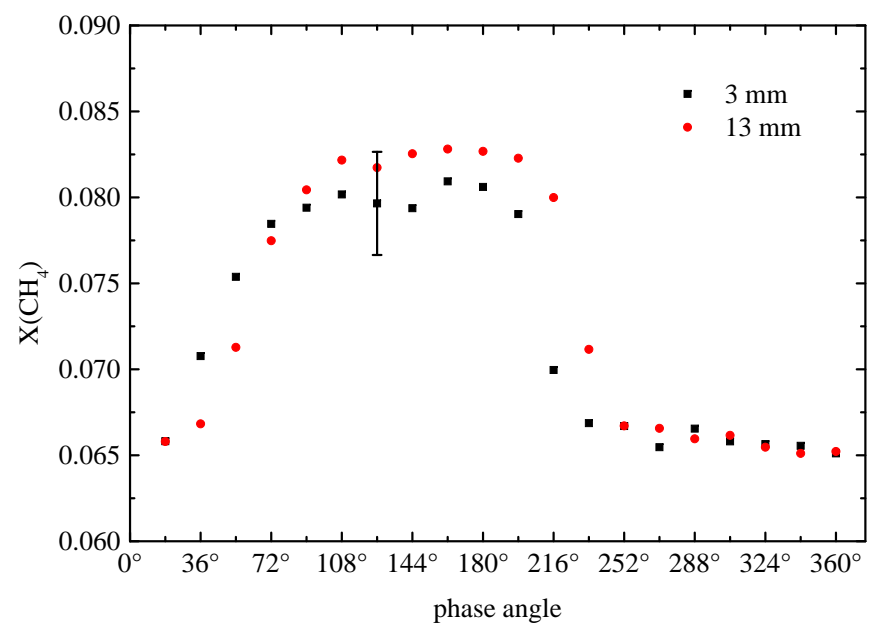

Figure 7: Periodical $\mathrm{CH}_{4}$ concentrations in the fresh gas at two different HAB.

of $5 \mathrm{~Hz}$ is presented. Figure 7 shows the phase resolved $\mathrm{CH}_{4}$ mole fractions in one period at two different HAB. The samples shown as black squares were measured close to the burner exit at $\mathrm{HAB}=3 \mathrm{~mm}$; the samples shown as red dots were measured at a HAB of $13 \mathrm{~mm}$ just upstream of the preheat zone. For a better clarity, only one error bar is representatively indicated for all measurements at the phase angle $126^{\circ}$. The definition of the phase angles has experimental reasons and is arbitrary regarding the oscillation. At the phase angle $18^{\circ}$, the concentrations at both heights are close to the value of the undisturbed flame of $\mathrm{X}\left(\mathrm{CH}_{4}\right)=0.0652$. At $36^{\circ}$, the concentration is significantly increased at $\mathrm{HAB}=3 \mathrm{~mm}$ due to the beginning of the $\mathrm{CH}_{4}$ pulse, whereas at the $\mathrm{HAB}$ of $13 \mathrm{~mm}$, no significant increase is detected until a phase angle of $54^{\circ}$. Between the phase angles $108^{\circ}$ and $198^{\circ}$ the concentrations at both heights have reached a maximum level of around 0.08. After the $\mathrm{CH}_{4}$ pulse, the concentrations decrease and remain at the minimum level between the phase angles $252^{\circ}$ and $18^{\circ}$.

The deviation of the maximum concentrations at the two different HAB might 
be explained by the signal reduction and post processing of the measured Raman spectra. Two specific factors were applied to these measurements. One factor is the afore mentioned daily calibration factor that was applied to all measurements of one day. Minor drifts of the fresh gas temperature due to the warming of the burner after ignition or the laser alignment over one day might lead to minor deviations from this factor. A second scaling factor was applied to the measurements just above the burner. Since the 1D-signals were partially blocked by the burner rim, the recorded spectra close to the burner rim were each scaled with a different factor in order to match the measured reference temperature. These factors can induce changes in the evaluated species concentrations due to the different dependencies of the Raman signals of the different species on the temperature.

A possible physical reason of this deviation might be the uncertainty of the mass flow controllers of around $1.5 \%$. The observerd difference is, however, still within the error limits.

The delays at the rising and falling edges of the pulse at $\mathrm{HAB}=13 \mathrm{~mm}$ compared to $\mathrm{HAB}=3 \mathrm{~mm}$ by approximately one phase interval correspond well with the time of $10 \mathrm{~ms}$ that it takes the flow to cover the distance of $10 \mathrm{~mm}$ at a velocity of around $1000 \mathrm{~mm} / \mathrm{s}$. In the case of $25 \%$ additional $\mathrm{CH}_{4}$, the mean flow velocity increases by only $1.6 \%$, which has no significant effect on the concentration profiles. The durations of both the increase and the decrease of the $\mathrm{CH}_{4}$ concentration between the constant minimum and maximum concentration levels are about $30 \mathrm{~ms}$ due to the diffusional transport that results from the induced concentration gradient. There is no difference in the gradients of the pulse detectable at the two heights.

An increasing fuel ratio in a premixed lean flame leads to enhanced heat re- 
lease and, thus, to increased flame propagation speed [41]. In the range of low equivalence ratios up to $\Phi=0.9$, this effect on the flame position is stronger than the increase in the flow velocity due to the additional fuel mass flow. As a result, the flame front moves towards the burner until it reaches a stable position again.

The displacement of the flame due to the equivalence ratio variation can be seen in the $\mathrm{OH}^{*}$-chemiluminescence measurements. Figure 8 shows the detected $\mathrm{OH}^{*}$ signals at two different phase angles. For a better comparison, the image is composed of two half images that are opposed along the central flame axis. The $\mathrm{OH}^{*}$ signals of all measurements were normalized to the overall minimum value and can therefore be qualitatively compared. At the phase angle $36^{\circ}$ the flame tip has the maximum distance of around $26 \mathrm{~mm}$ from the burner. This phase angle is just before the $\mathrm{CH}_{4}$ pulse reaches the flame front as it was seen in Fig. 7. The minimum distance from the burner is found $180^{\circ}$ later at $216^{\circ}$ which is at the end of the $\mathrm{CH}_{4}$ pulse. The total displacement of the flame tip is $6.5 \mathrm{~mm}$. The $\mathrm{OH}^{*}$ signal at $216^{\circ}$ is stronger compared to the signal at $36^{\circ}$ as a result of the increased equivalence ratio.

A more detailed insight into the flame front behavior is provided by the results from the 1D-Raman measurements. Figure 9 shows the $\mathrm{CH}_{4}$ concentration profiles along the central axis at six different phase angles. Note that the time intervals between these phase angles vary. The position of the preheat zone at each phase angle can be identified by the steep gradient of the $\mathrm{CH}_{4}$ concentration.

The periodical flame front behavior can be described by the analysis of the different $\mathrm{CH}_{4}$ concentration profiles. At $36^{\circ}$, when the flame tip is at the maximum distance from the burner, the $\mathrm{CH}_{4}$ concentration is at the minimum level of around $6.5 \%$ across and upstream from the flame front. However, between $\mathrm{HAB}=2$ and 


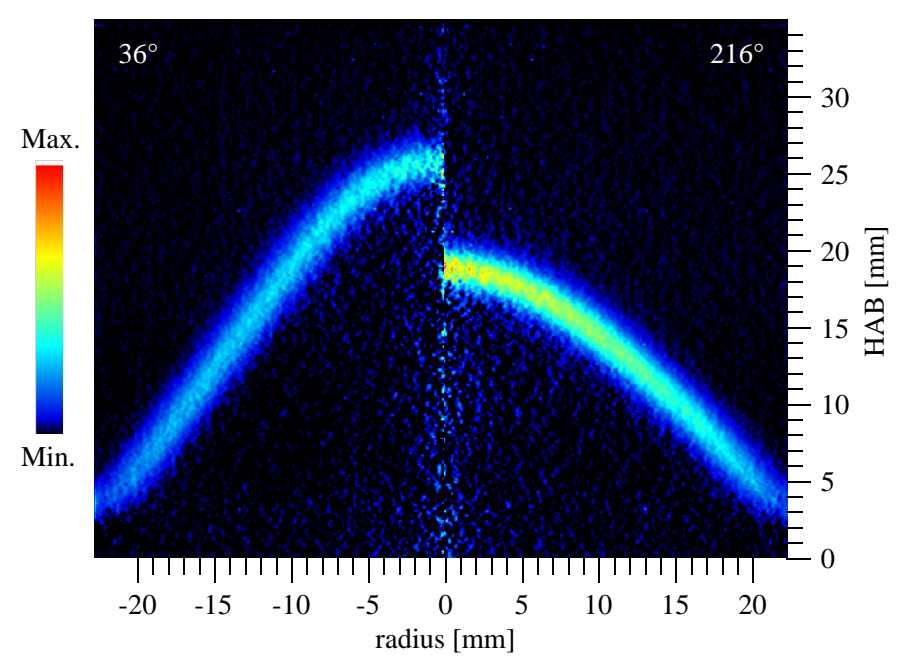

Figure 8: $\mathrm{OH}^{*}$ signal at two different phase angles.

$\mathrm{HAB}=14 \mathrm{~mm}$ a slight increase can be found which indicates the beginning of the $\mathrm{CH}_{4}$ pulse. At $72^{\circ}$, the $\mathrm{CH}_{4}$ pulse has reached the flame front causing a displacement of the flame tip towards the burner, even though the $\mathrm{CH}_{4}$ concentration has not yet reached the maximum level at the beginning of the preheat zone. The flame tip moves further towards the burner between the phase angles $72^{\circ}$ and $144^{\circ}$ when the $\mathrm{CH}_{4}$ concentration is at the maximum of around $8 \%$. At $216^{\circ}$, one can see that the $\mathrm{CH}_{4}$ concentration is still at the maximum at the beginning of the preheat zone and is therefore also across the flame front. The concentration further upstream towards the burner decreases as the $\mathrm{CH}_{4}$ pulse has passed. At this phase angle, the flame tip is at the minimum distance from the burner. With the subsequent decrease of the $\mathrm{CH}_{4}$ concentration across the flame front and the resulting lower flame propagation speed, the flame tip moves downstream until it reaches a steady state again at the maximum distance from the burner.

The effects of the equivalence ratio oscillations can also be found in the pro- 


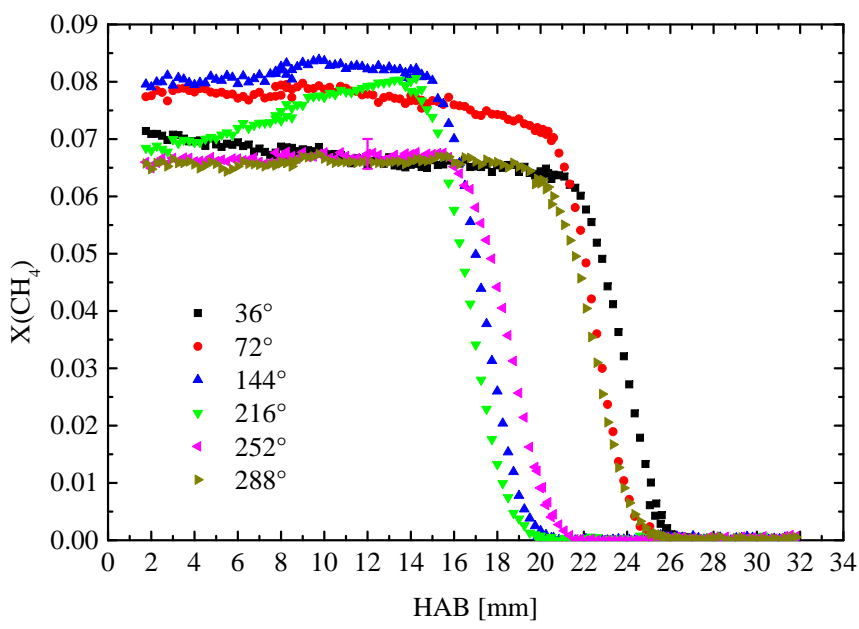

Figure 9: $\mathrm{CH}_{4}$ concentration profiles at different phase angles at a frequency of $5 \mathrm{~Hz}$ and $25 \%$ additional fuel.

files of other species. As a representative example, the $\mathrm{H}_{2}$ concentrations profiles along the central axis are plotted in Fig. 10 at the phase angles $36^{\circ}$ and $216^{\circ}$ together with the according $\mathrm{CH}_{4}$ profiles. The maximum $\mathrm{H}_{2}$ concentration is found close before the methane is completely consumed in the reaction zone. As expected, more $\mathrm{H}_{2}$ is formed in the case with the higher equivalence ratio at $216^{\circ}$. The consumption and formation mechanisms of $\mathrm{CH}_{4}$ and $\mathrm{H}_{2}$ are rather different. The gradient of the $\mathrm{CH}_{4}$ concentration in the preheat zone is caused by the diffusional transport of $\mathrm{CH}_{4}$ from the fresh gas to the reaction zone. $\mathrm{H}_{2}$, on the other hand, is formed close to the reaction zone as an intermediate species during the combustion of $\mathrm{CH}_{4}$ [42]. Due to the resulting concentration gradient, $\mathrm{H}_{2}$ diffuses towards the fresh gas against the convective flow direction and towards the burned gas in flow direction. The question is, if the different effects of convective and diffusional transport during equivalence ratio oscillations have an impact on the structure of the flame front. 


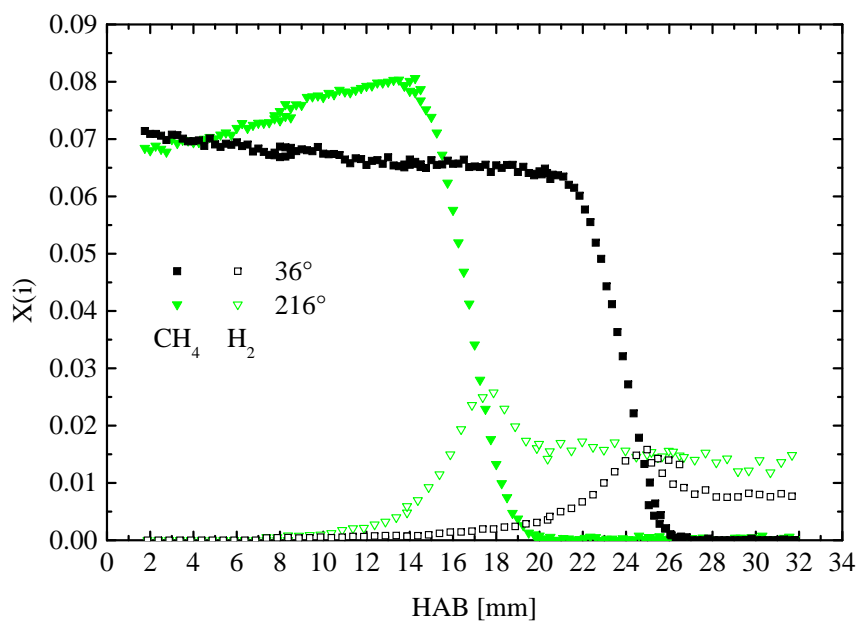

Figure 10: $\mathrm{CH}_{4}$ and $\mathrm{H}_{2}$ concentration profiles at two phase angles at a frequency of $5 \mathrm{~Hz}$ and $25 \%$ additional fuel.

The variation of the equivalence ratio in the fresh gas can be well observed by the profile of the methane concentration up to the preheat zone. However, an analysis of the mixture and its variation across the flame front is difficult due to the decrease of the methane concentration in the preheat zone and the following consumption in the reaction zone. A spatial and temporal analysis of the mixture can be made by the mixture fraction as a measure for the ratio of fuel to air. Figure 11 shows the mixture fraction in dependence on the height above the burner for the phase angles $36^{\circ}, 54^{\circ}$ and $72^{\circ}$. The two representative error bars for the fresh gas and the burned gas at the phase angle $36^{\circ}$ are relatively high as mentioned before in the case of the stationary flame. The analysis of the results is supported by the profile of the methane concentration in Figs. 7 and 9 since the mixture fraction is proportional to the methane concentration.

In Fig. 9, it was seen that the methane concentration was already slightly increased up to $\mathrm{HAB}=14 \mathrm{~mm}$ due to the beginning of the methane pulse. This 


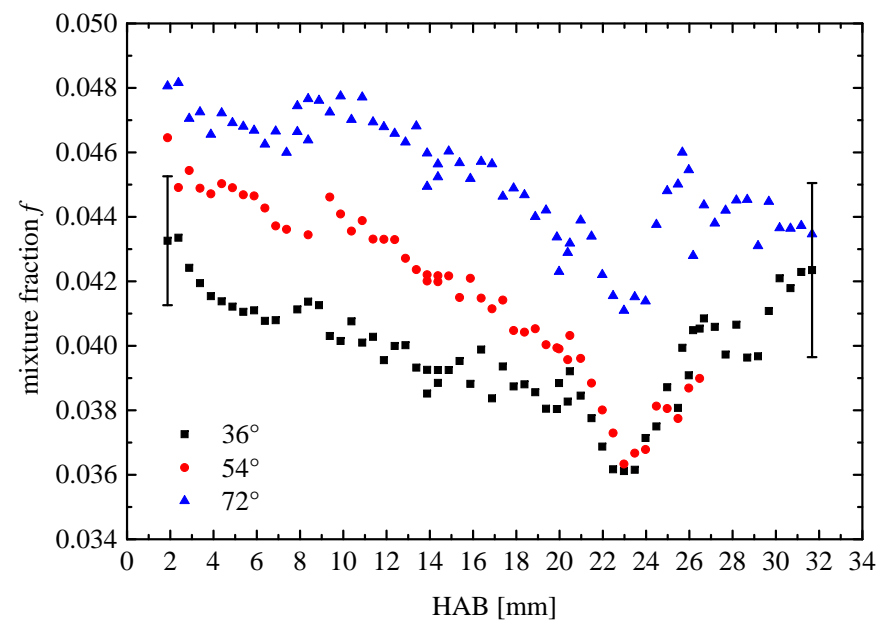

Figure 11: Profiles of the mixture fraction for three different phase angles at a frequency of $5 \mathrm{~Hz}$ and $25 \%$ additional fuel.

increase can also be observed in the profile of the mixture fraction in Fig. 11. From $14 \mathrm{~mm}$ onwards the profile represents the mixture fraction in the case of the stationary flame front as shown in Fig. 6. The mixture fraction remains constant up to around $\mathrm{HAB}=21 \mathrm{~mm}$, decreases in the following to the minimum in the preheat zone at around $\mathrm{HAB}=24 \mathrm{~mm}$ and increases again up to an almost constant value in the oxidation layer from $\mathrm{HAB}=27 \mathrm{~mm}$ on.

At the phase angle $54^{\circ}$ an increase of the mixture fraction can already be seen within the preheat zone up to around $\mathrm{HAB}=23 \mathrm{~mm}$. The time delay between the phase angles $36^{\circ}$ and $54^{\circ}$ is $10 \mathrm{~ms}$ in which the fresh gas covers a distance of about $10 \mathrm{~mm}$. This is in agreement to the observation of the advancing methane pulse from $\mathrm{HAB}=14$ to $24 \mathrm{~mm}$. Only one phase angle later, at $72^{\circ}$, an increased mixture fraction can be observed across the whole flame front.

In order to investigate the temporal relation of the equivalence ratio oscillations and the reaction kinetics in the reaction zone, the progression of the mixture 


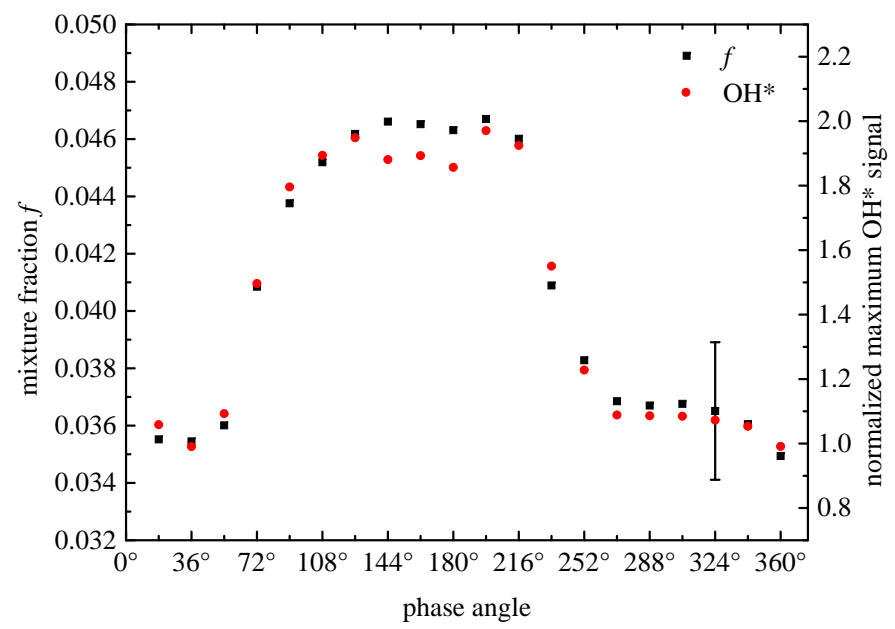

Figure 12: phase correlation of the mixture fraction and the $\mathrm{OH}^{*}$ signal at a frequency of $5 \mathrm{~Hz}$ and $25 \%$ additional fuel.

fraction $f$ and the $\mathrm{OH}^{*}$ signal are plotted in Fig. 12 over one period. The value of the mixture fraction in this case is the local minimum in the preheat zone as it was seen in Fig. 6 because it can be well identified and is in vicinity of the reaction zone. The $\mathrm{OH}^{*}$ signal is normalized to the minimum detected signal. The general appearance of both plots is similar to the periodical progression of the $\mathrm{CH}_{4}$ concentration that was found in Fig. 9. Both values alternate between a maximum and a minimum level during one period, though there is no phase delay between the rising and falling edges within the limits of the measurement accuracy. We therefore assume that the underlying reaction kinetics for the formation of $\mathrm{OH}^{*}$, i.e. the heat release, instantaneously follow the equivalence ratio oscillations.

The formation of $\mathrm{H}_{2}$ is shown in Fig. 13 in comparison with the $\mathrm{OH}^{*}$ signal. The $\mathrm{H}_{2}$ value is the maximum that is found in the flame front in vicinity of the reaction zone. The progression of the two values is also congruent within the limits of the measurement accuracy as it was the case in Fig. 12. The observations 


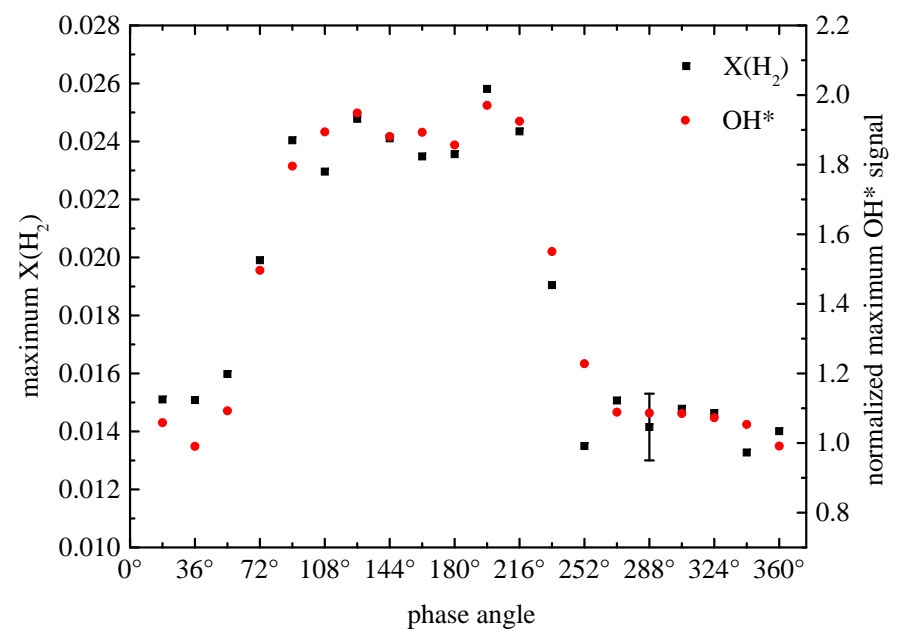

Figure 13: Phase correlation of the $\mathrm{OH}^{*}$ signal and the maximum $\mathrm{H}_{2}$ concentration at a frequency of $5 \mathrm{~Hz}$ and $25 \%$ additional fuel.

of Figs. 12 and 13 lead to the assumption that there is no significant phase or time delay between the mixture fraction oscillations and the formation of $\mathrm{H}_{2}$.

To investigate the effects of mass diffusion on the flame front, the concentrations of $\mathrm{CH}_{4}$ (left scale) and $\mathrm{H}_{2}$ (right scale) are shown in Fig. 14 over one period at the same position at the beginning of the preheat zone. The measurement location is virtually fixed in relation to the moving flame front about $4 \mathrm{~mm}$ upstream of the $\mathrm{OH}^{*}$ maximum. The position was chosen as a compromise between a large distance from the reaction zone and a significantly high $\mathrm{H}_{2}$ concentration. The values were obtained by averaging four adjacent measurement volumes corresponding to a length of $1 \mathrm{~mm}$. In terms of the flame history, the $\mathrm{CH}_{4}$ is transported from that location to the reaction zone and the $\mathrm{H}_{2}$ subsequently diffuses from the reaction zone to that position. One can clearly see that there is a time delay of around $30 \mathrm{~ms}$ between the rising edges of the concentrations due to the combined effects of flame propagation and diffusion. The $\mathrm{H}_{2}$ concentration profile cannot 


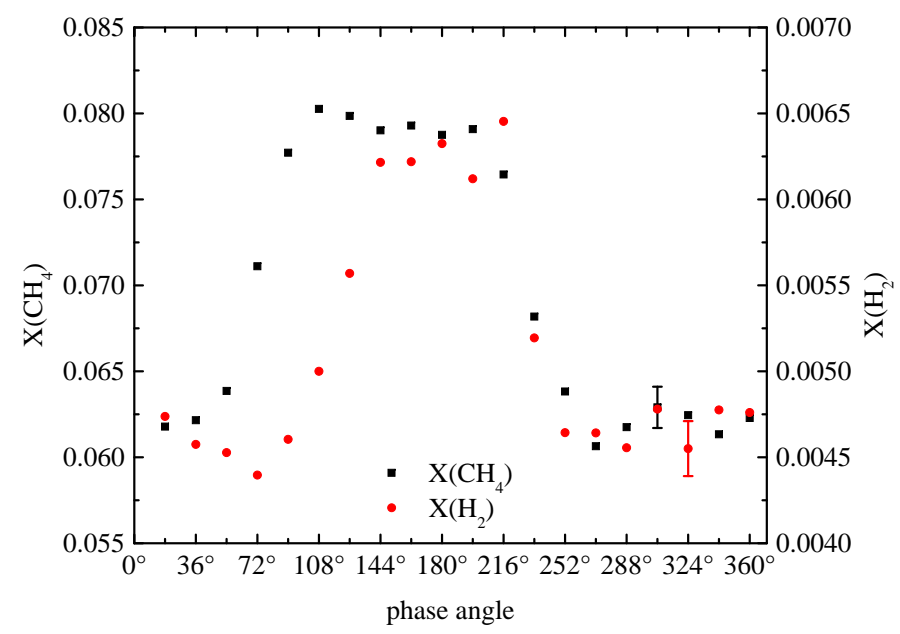

Figure 14: $\mathrm{CH}_{4}$ and $\mathrm{H}_{2}$ concentrations at the beginning of the preheat zone at a frequency of $5 \mathrm{~Hz}$ and $25 \%$ additional fuel.

follow the disturbance instantaneously while the flame is moving upstream but reaches a quasi-steady maximum level between the phase angles $144^{\circ}$ and $216^{\circ}$. At the falling edge, after the $\mathrm{CH}_{4}$ pulse, no significant phase delay is visible.

A comparison of the velocities of the different transport mechanisms shall give a clue about the concurrent phenomena in the flame front. For a detailed analysis, however, complex numerical simulation would be needed, which were not part and goal of this work. Therefore, only rough estimations of the velocities will be given here. The mean velocity of the convective transport of the fresh gas $v_{u}$ can be calculated based on the volume flow and the burner dimensions to $v_{u}=1.018$ $\mathrm{m} / \mathrm{s}$ for the stationary flame. In the case of a pulsation with $25 \%$ additional $\mathrm{CH}_{4}$, the mean fresh gas flow velocity increases by $1.6 \%$.

The velocity of the flame propagation can be estimated from the geometric relations of the vectors of the fresh gas velocity and the laminar flame speed that is directed normally to the flame surface [43]. Thus, the laminar flame speed of the 
stationary flame was determined to $s_{l}=0.613 \mathrm{~m} / \mathrm{s}$. In the case of $25 \%$ additional $\mathrm{CH}_{4}$, the laminar flame speed increases to $0.77 \mathrm{~m} / \mathrm{s}$, which is equal to a relative increase by about $20 \%$ and higher than the increase of the flow velocity of the fresh gas. Consequently, the flame moves towards the burner.

An estimation of the diffusive transport of mass and heat is more difficult since the diffusion velocity coefficients are non-linearly dependent on the temperature, which strongly varies across the flame front. For a rough estimation we assume a constant mean temperature of $700 \mathrm{~K}$ in the preheat zone and calculate the thermal conductivity $\lambda$ in air as proposed by Lemmon and Jacobsen [44] for a dilute gas. A formula for the required viscosity $\mu$ is also given in [44]. If we further neglect the fuel contained in the fresh gas, the calculation yields $\lambda=0.051 \mathrm{~W} /(\mathrm{m} \mathrm{K})$. The thermal diffusivity is given by $\alpha=\lambda /\left(\rho c_{p}\right)$, which yields $\alpha=15 \mathrm{~cm}^{2} / \mathrm{s}$ with the assumption of a constant density $\rho$ and heat capacity $c_{p}$.

The mass diffusivity $D$ of $\mathrm{CH}_{4}$ is expected to be similar to the thermal diffusivity as it was seen in the correlation shown in Fig. 5. A rough estimation of the diffusivity of $\mathrm{CH}_{4}$ in air at $700 \mathrm{~K}$ can be made using the formula proposed by Fairbanks and Wilke [45]. The binary diffusion coefficients for $\mathrm{CH}_{4}$ in $\mathrm{O}_{2}$ and $\mathrm{CH}_{4}$ in $\mathrm{N}_{2}$ can be calculated by the definition given in Hirschfelder et al. [46] based on Lennard-Jones potential calculations. This results in a diffusivity of $D_{C H 4, \text { air }}=14.5 \mathrm{~cm}^{2} / \mathrm{s}$ which is indeed similar to the estimated thermal diffusivity.

The calculation of the diffusivity of $\mathrm{H}_{2}$ in air under the same conditions yields $D_{H 2, \text { air }}=47.3 \mathrm{~cm}^{2} / \mathrm{s}$. The $\mathrm{H}_{2}$ diffusion is therefore around three times faster than the $\mathrm{CH}_{4}$ diffusion. The mean squared displacement $s=\sqrt{2 D t}$ [47] of $\mathrm{H}_{2}$ in one direction is $s=97.3 \mathrm{~mm}$ per second. Thus, the $\mathrm{H}_{2}$ diffusion and the flame displacement run parallel to each other with similar velocities, with the flame 
displacement being slightly faster, until the diffusion can catch up when the flame has reached a stable position again.

The wavelength $l$ of the oscillation at $5 \mathrm{~Hz}$ with a flow velocity of around $v=1000 \mathrm{~mm} / \mathrm{s}$ is equal to $l=200 \mathrm{~mm}$ which is much longer than the flame height of around $L=20 \mathrm{~mm}$ and the flame thickness of around $\delta=10 \mathrm{~mm}$. Due to the relatively long duration of the opened and closed states of the valve in comparison to the time scales of flame propagation and diffusional transport processes, the flow reaches stationary conditions for about five phase intervals according to $50 \mathrm{~ms}$ from $108^{\circ}$ to $198^{\circ}$ in the case of the opened valve and for about $70 \mathrm{~ms}$ from $252^{\circ}$ to $18^{\circ}$ in the case of the closed valve (see Fig. 7). However, the flame front structure only reaches quasi-steady states for about three phase intervals (or $30 \mathrm{~ms}$ ) from $144^{\circ}$ to $198^{\circ}$ while the valve is open and for about $70 \mathrm{~ms}$ without additional methane.

\subsection{2. $20 \mathrm{~Hz},+25 \% \mathrm{CH}_{4}$}

In a further step, a flame with the same additional amount of fuel of $25 \%$ as described before but with a higher oscillation frequency of $20 \mathrm{~Hz}$ is analyzed. The periodical variation of $\mathrm{CH}_{4}$ along the central axis is shown in Fig. 15 at four phase angles. A representative error bar is only shown for one phase angle at a height above the burner of $10 \mathrm{~mm}$ for the sake of clarity. The concentration profiles at $36^{\circ}$ and $216^{\circ}$ represent the phase angles with the minimum and maximum distance from the burner, respectively. The $\mathrm{CH}_{4}$ mole fraction varies between 6.6 and $8 \%$ as it was also observed in the $5 \mathrm{~Hz}$ case.

The effect of the additional fuel on the flame displacement as already observed in the case of $5 \mathrm{~Hz}$ can be clearly seen. The flame reaches the minimum position at $36^{\circ}$ at the end of the pulse and the maximum position at $216^{\circ}$ just before the 


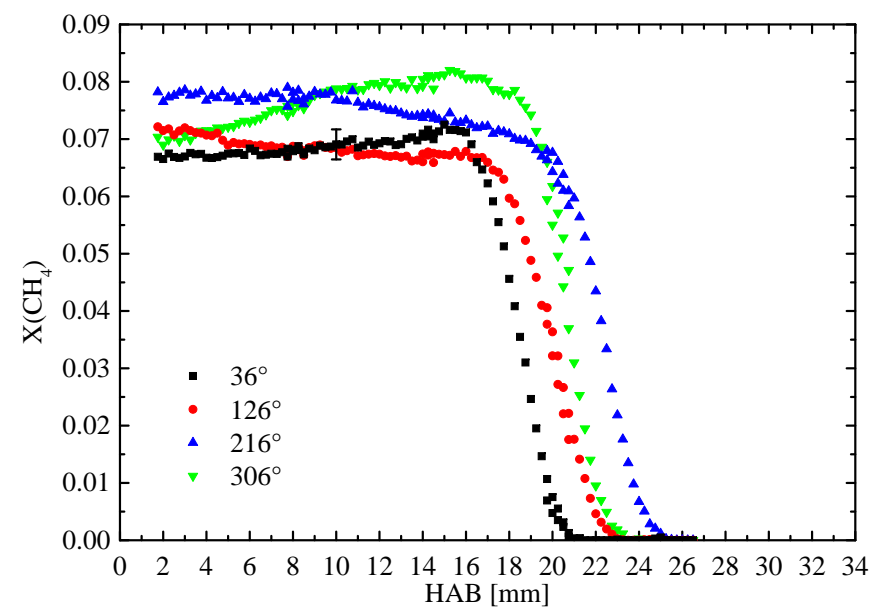

Figure 15: $\mathrm{CH}_{4}$ concentration profiles at different phase angles at a frequency of $20 \mathrm{~Hz}$ and $25 \%$ additional fuel.

next pulse reaches the flame front. The phase angle at $126^{\circ}$ represents a state without additional fuel across the flame front between two pulses. The flame is moving from the position at $36^{\circ}$ towards the maximum distance at $216^{\circ}$. The next incoming pulse can already be seen in the increasing $\mathrm{CH}_{4}$ concentration from the flame front to the burner exit. The flame at $306^{\circ}$, on the other hand, represents a state with a higher mixture fraction across the flame front and is moving towards the minimum $\mathrm{HAB}$ at $36^{\circ}$.

The recorded $\mathrm{OH}^{*}$ chemiluminescence signal at the flame tip was used to quantitatively determine the flame displacement. The results are shown in Fig. 16 as blue triangles showing the $\mathrm{HAB}$ of the maximum $\mathrm{OH}^{*}$ signal over one period (scale on the right side). The profile is almost sinusoidal with the minimum at $36^{\circ}$ and the maximum at $234^{\circ}$. The difference in the maximum HAB that was observed in the $\mathrm{CH}_{4}$ profiles and the maximum in the $\mathrm{OH}^{*}$ signal is due to different criteria for the determination. In the case of the $\mathrm{CH}_{4}$ profiles, the slope of 


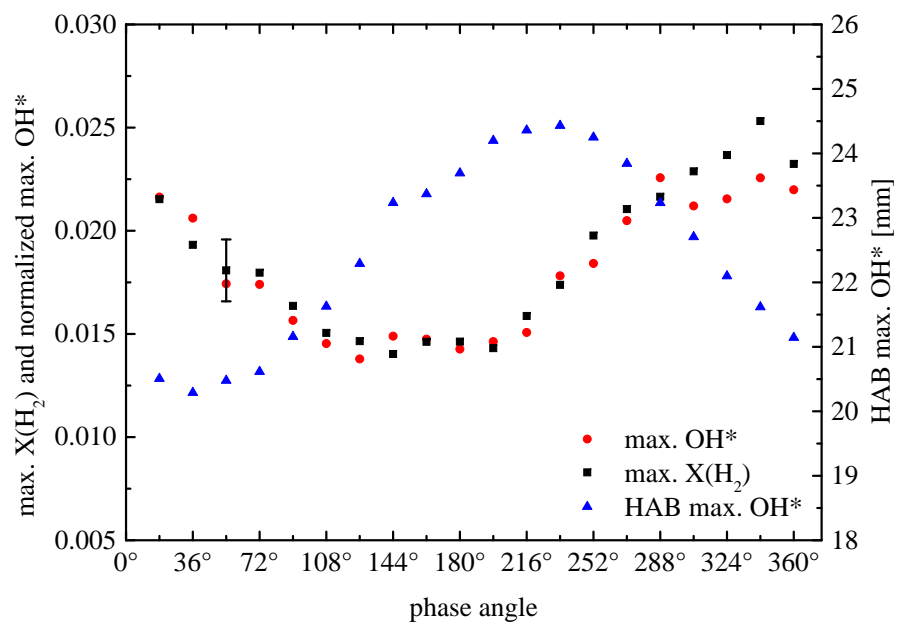

Figure 16: Phase correlation of the maximum $\mathrm{H}_{2}$ concentration, the maximum $\mathrm{OH}^{*}$ signal and the position of maximum $\mathrm{OH}^{*}$ signal at a frequency of $20 \mathrm{~Hz}$ and $25 \%$ additional fuel.

the decreasing $\mathrm{CH}_{4}$ concentration in the preheat zone was used as a marker for the $\mathrm{HAB}$. The $\mathrm{OH}^{*}$, however, is formed in the reaction zone close to the complete consumption of the $\mathrm{CH}_{4}$. The total flame displacement is $4.1 \mathrm{~mm}$, which is significantly less than at $5 \mathrm{~Hz}$, though the pulse strength reaching the flame front is similar.

The maximum $\mathrm{H}_{2}$ concentration in the flame front and the normalized maximum $\mathrm{OH}^{*}$ signal are also shown in Fig. 16. The two profiles are also almost sinusoidal and are in phase throughout the period. However, a phase shift of around $90^{\circ}$ is observed in comparison to the flame displacement, represented by the $\mathrm{HAB}$ of the $\mathrm{OH}^{*}$ signal, which demonstrates the complex interaction of kinetic processes and flame propagation. 


\subsection{3. $40 \mathrm{~Hz},+50 \% \mathrm{CH}_{4}$}

At higher frequencies, several effects occur that alter the form of the pulsation and the flame response. The $\mathrm{CH}_{4}$ concentration gradients at the rising and falling edges converge due to shorter wavelengths of the pulsation with higher frequencies. However, the effect of diffusion in and against the flow direction leads to a sinusoidal pulse form with a reduced effective pulse strength. This effect is representatively shown in Fig. 17 for the case of 50\% additional fuel in dependence on the frequency. The curves show the variation of the $\mathrm{CH}_{4}$ concentration in one period at $\mathrm{HAB}=13 \mathrm{~mm}$ just upstream of the preheat zone. The data of the middle curve (black squares) are the mean $\mathrm{CH}_{4}$ concentration values that were measured at the different oscillation frequencies. They are constant at around 0.08 within the limits of the measurement accuracy. The lower and upper traces mark the minimum and maximum $\mathrm{CH}_{4}$ concentrations. There is a trend in both curves to approach the mean value with increasing frequency. However, there is still a significant variation in the $\mathrm{CH}_{4}$ concentration that reaches the flame front at $40 \mathrm{~Hz}$.

If the oscillation frequency is sufficiently increased, the wavelength approximates the length scales of the flame height and the flame front thickness. At $40 \mathrm{~Hz}$, for example, the wavelength is $25 \mathrm{~mm}$ (at a flow velocity of $1 \mathrm{~m} / \mathrm{s}$ ), which is similar to the flame height. Thus, equivalence ratio gradients are induced in the flame front in vertical direction as in a stratified flame. Consequently, the laminar flame speed varies along the flame cone resulting in a non-uniform flame propagation in or against the direction of the flame displacement that arises from the varying volume flow, depending on the phase angle. The effect of the non-uniform flame propagation can be seen in the $\mathrm{OH}^{*}$ images composed to a video as a slight periodically changing curvature along the cone. However, it is difficult to see it in 


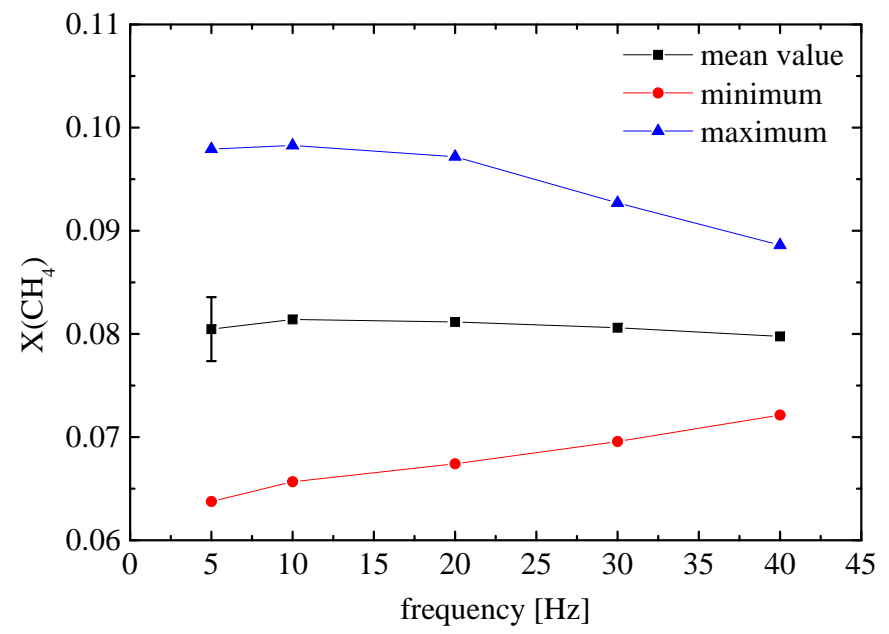

Figure 17: Effective $\mathrm{CH}_{4}$ variation in dependence on the frequency for the case of $50 \%$ additional $\mathrm{CH}_{4}$.

images next to each other and therefore not shown in this paper. In addition to this non-uniformity, the time for the flame to adjust to the disturbance by a changed flame speed diminishes with increasing frequency. All these effects affect the total displacement of the flame. Figure 18 shows the maximum flame displacement for three different amounts of additional $\mathrm{CH}_{4}$ in dependence on the frequency. At $5 \mathrm{~Hz}$, there is a significant displacement of the flame tip even with a pulsation of only $10 \%$ additional $\mathrm{CH}_{4}$. The displacement of around $7 \mathrm{~mm}$ in the case of $25 \%$ additional $\mathrm{CH}_{4}$ was already observed in Figs. 8 and 9. With 50\% additional $\mathrm{CH}_{4}$, however, the displacement is only slightly higher than with $25 \%$. Two effects gain weight in this case. First, the fresh gas velocity increases by about $3.2 \%$ and is directed contrary to the flame propagation, and, second, the laminar flame speed increases less approaching stoichiometry.

With increasing frequency, the flame displacement decreases as it was observed for the $20 \mathrm{~Hz}$ case in comparison to $5 \mathrm{~Hz}$. The decline is relatively weak 


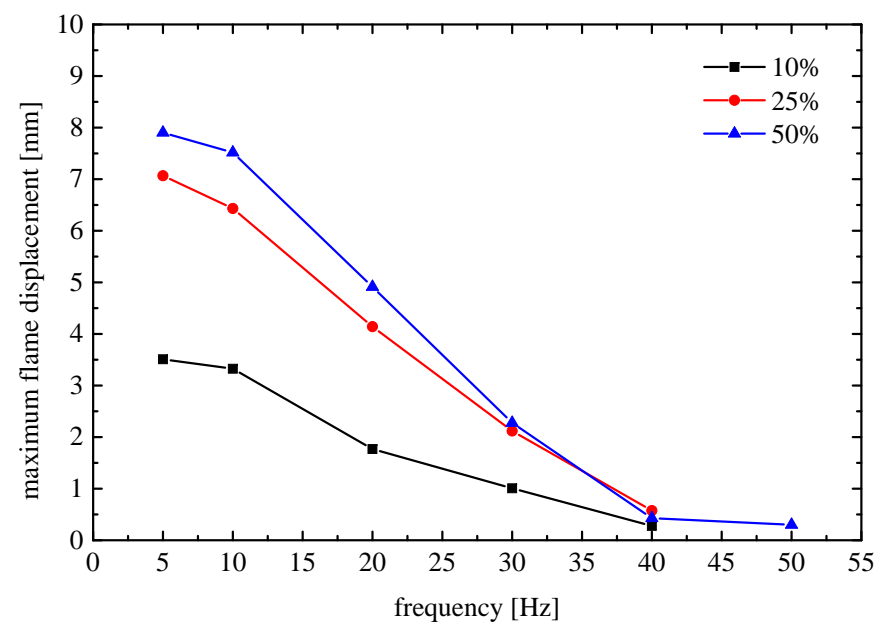

Figure 18: Flame displacement in dependence on the frequency for three different amounts of additional $\mathrm{CH}_{4}$.

between $5 \mathrm{~Hz}$ and $10 \mathrm{~Hz}$, but gets stronger with increasing frequency. From $40 \mathrm{~Hz}$ on, no displacement of the flame tip could be detected anymore independently of the pulse strength. The remaining value at $40 \mathrm{~Hz}$ is due to the scatter of the measurements.

To investigate the impact of oscillations with higher frequencies on the flame front structure, we take a closer look at the flame with a frequency of $40 \mathrm{~Hz}$ and $50 \%$ additional $\mathrm{CH}_{4}$. Figure 19 shows the $\mathrm{CH}_{4}$ concentration profiles from the burner to the flame tip at five different phase angles. One can clearly see the variation of the equivalence ratio along the central burner axis up to the flame front. The estimated wavelength of around $25 \mathrm{~mm}$ at these conditions can also be found if the run of the profiles in the fresh gas region is extended theoretically across the flame front from $16 \mathrm{~mm}$ onwards. The reaction zone is located at around $\mathrm{HAB}=21 \mathrm{~mm}$ and does not change its position throughout the period. The gradients in the preheat zone are steeper the higher the fuel concentration at 


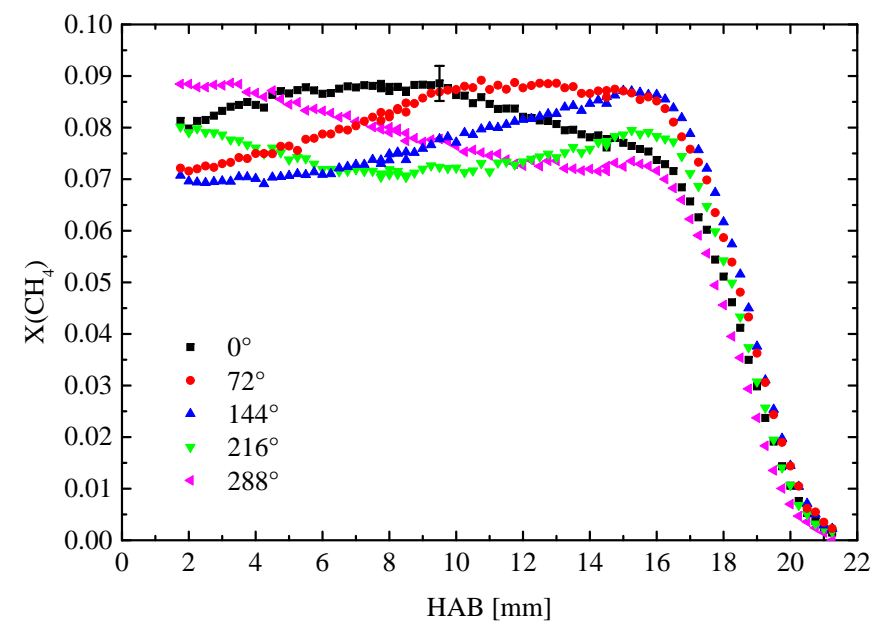

Figure 19: $\mathrm{CH}_{4}$ concentration profiles at $40 \mathrm{~Hz}$ and $50 \%$ additional fuel.

the beginning of the preheat zone at around $\mathrm{HAB}=16 \mathrm{~mm}$.

The correlation of the mixture fraction inside the flame front and the formation of $\mathrm{OH}^{*}$ is shown in Fig. 20 in comparison the $5 \mathrm{~Hz}$ case that was shown before in Fig. 12. The value of the mixture fraction is taken at the local minimum in the preheat zone. The two profiles are in phase throughout the period within the limits of accuracy. This underlines the evidence that the heat release and, thus, the formation of $\mathrm{OH}^{*}$ instantaneously follow the induced equivalence ratio oscillations as it was already observed in the $5 \mathrm{~Hz}$ case.

The times scale of the chemical kinetics in the flame front is still much faster than the induced equivalence ratio oscillation. This is also valid for the formation of $\mathrm{H}_{2}$, which is found almost at the same position as the $\mathrm{OH}^{*}$ (see Figs. 3 and 4). The correlation of both species is plotted in Fig. 21 over one period. The $\mathrm{H}_{2}$ mole fraction was averaged over four adjacent measurement values between $19<\mathrm{HAB}<20 \mathrm{~mm}$ in order to reduce the scatter. The two profiles are also in phase throughout the period. 


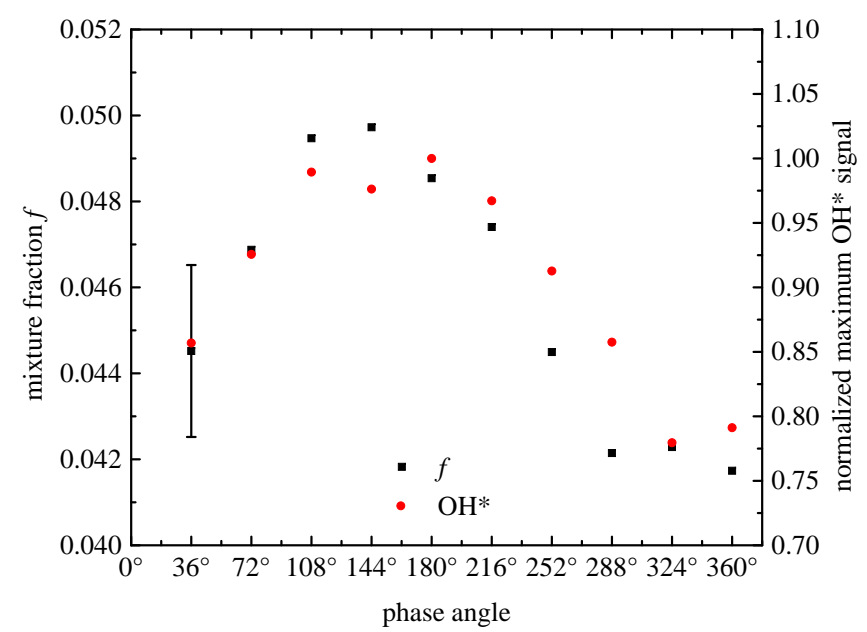

Figure 20: phase correlation of the mixture fraction and the $\mathrm{OH}^{*}$ signal at a frequency of $40 \mathrm{~Hz}$ and $50 \%$ additional fuel.

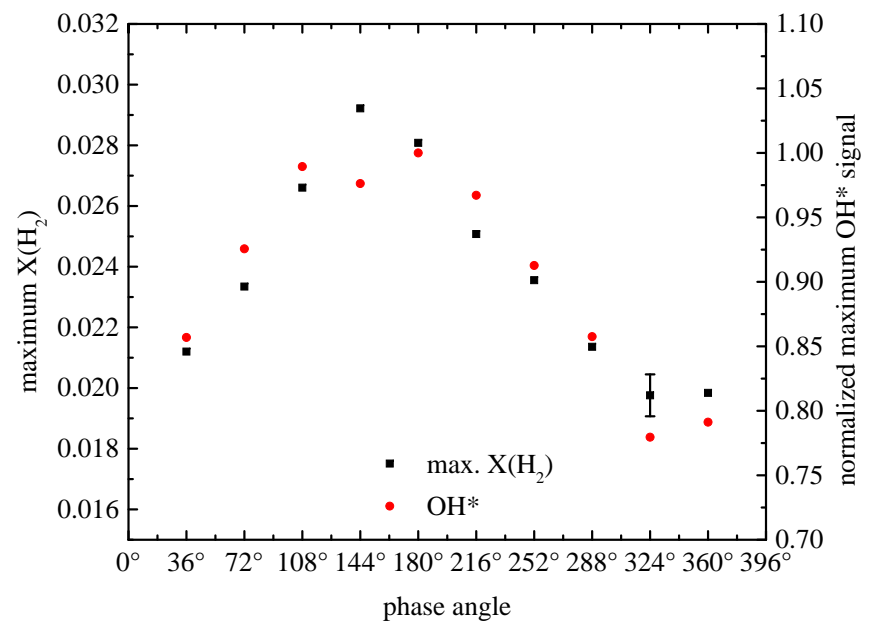

Figure 21: Phase correlation of the maximum $\mathrm{OH}^{*}$ signal and the maximum $\mathrm{H}_{2}$ concentration at a frequency of $40 \mathrm{~Hz}$ and $50 \%$ additional fuel. 
With the absence of flame propagation and the kinetics on a much shorter time scale, this leaves the investigation of the diffusional transport processes within the flame front during equivalence ratio oscillations. The effects of diffusion is demonstrated by the comparison of the profiles of $\mathrm{CH}_{4}$ and $\mathrm{H}_{2}$ in the preheat zone as it was already shown in Fig. 14 for the case of $5 \mathrm{~Hz}$ and $25 \%$ additional fuel. Figure 22 shows the concentrations of $\mathrm{CH}_{4}$ (left scale) and $\mathrm{H}_{2}$ (rights scale) $4 \mathrm{~mm}$ upstream of the maximum $\mathrm{OH}^{*}$ signal in dependence on the phase angle. One can see that the two profiles are out of phase throughout the period. The $\mathrm{H}_{2}$ concentration follows the $\mathrm{CH}_{4}$ concentration with a significant delay both at the rising and falling edge of the methane pulse. The flame front structure, which is mainly determined by diffusion and convection, cannot adjust to the equivalence ratio oscillation fast enough.

These observations confirm by trend the findings of numerical simulations that focused on the effects of equivalence ratio oscillations in particular as carried out by Shreekrishna and Lieuwen [14]. Based on their numerical results, they stated that a flame can no longer be described by sequential steady flames beyond a certain frequency of equivalence ratio oscillations with period durations in the order of the diffusional time scales within the flame front.

\section{Summary and Conclusions}

The response of a perfectly premixed lean laminar $\mathrm{CH}_{4} /$ air-flame to modulated equivalence ratio oscillations was experimentally investigated in detail by complementary optical and laser based measurement techniques. The flame was operated at a pressure of $70 \mathrm{mbar}$ in order to enable measurements with a spatial resolution of the flame front structure and at oscillation wavelengths in the or- 


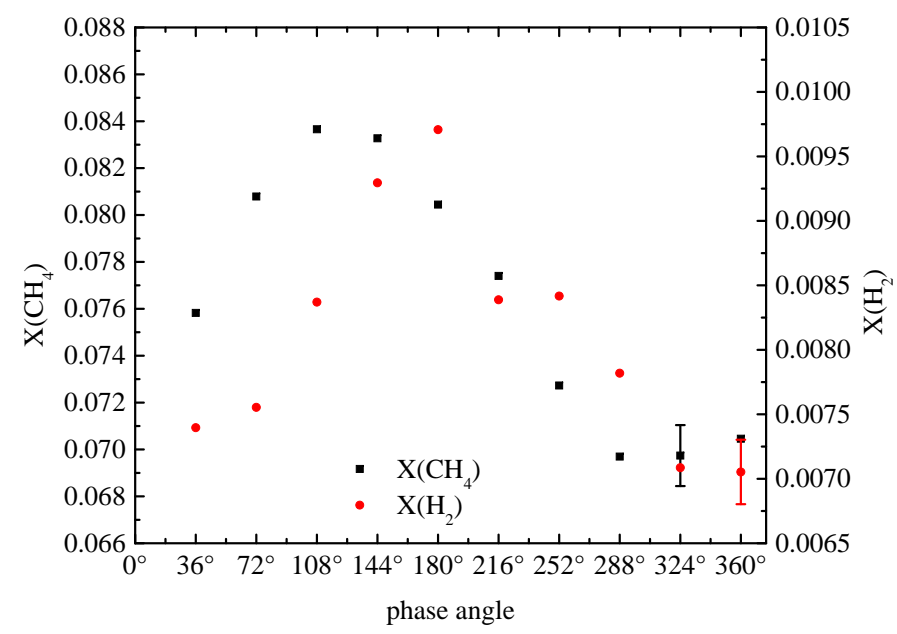

Figure 22: $\mathrm{CH}_{4}$ and $\mathrm{H}_{2}$ concentrations at the beginning of the preheat zone at a frequency of $40 \mathrm{~Hz}$ and $50 \%$ additional fuel.

der of magnitude of the flame thickness. $\mathrm{OH}^{*}$-chemiluminescence was detected for the visualization of the shape and position of the flame front. One-dimensional laser Raman scattering was applied for the quantitative determination of the major species concentrations, the mixture fraction and the temperature along the central burner and flame axis. The flame behavior was extensively investigated in a parametric study by variation of the frequency and amplitude of the oscillation.

The results reveal a complex interaction of the effects of flame propagation and diffusional transport processes on the flame front structure in dependence on the frequency of the equivalence ratio modulation. For low frequencies it was observed that the superposition of flame displacement and diffusion has a strong impact on the flame front structure as both processes take place on similar time scales. The flame cannot be described by quasi-steady states while the flame is changing its position due to enhanced flame propagation. With increasing frequency, the effective pulse amplitude is reduced due to the diffusional transport in 
and against the flow direction. Also, the flame displacement decreases because of the reduced time that is left for the flame to adjust to the oscillating laminar flame speed. For sufficiently high frequencies it was found that the flame tip does not change its position anymore even with significant equivalence ratio oscillations reaching the flame front. However, the species profiles reveal an unsteady phase dependent flame front structure throughout the oscillation period. The flame cannot be described by quasi-steady flame profiles at any phase.

The results provide a detailed insight into the flame structure and behavior and form a unique data set for the validation of numerical simulation models.

\section{Acknowledgments}

The experiments were conducted within the Collaborative Research Center 606. The funding of the Deutsche Forschungsgemeinschaft is gratefully acknowledged. The authors would like to thank P. Kutne, U. Stopper and J. Zanger for their help in the laboratory and the evaluation procedure.

\section{References}

[1] Y. Huang, V. Yang, Prog. Energ. Combust. Sci. 35 (2009) 293-364.

[2] S. Candel, Proc. Combust. Inst. 29 (2002) 1-28.

[3] T. Lieuwen, B. T. Zinn, Proc. Combust. Inst. 27 (1998) 1809-1816.

[4] A. P. Dowling, S. Hubbard, Proc. Inst. Mech. Engrs. (A) 214 (2000) $317-$ 332.

[5] W. Meier, P. Weigand, X. R. Duan, R. Giezendanner-Thoben, Combust. Flame 150 (2007) 2-26. 
[6] H. M. Altay, R. L. Speth, D. E. Hudgins, A. F. Ghoniem, Combust. Flame 156 (2009) 2106-2116.

[7] A. A. Putnam, Combustion-driven oscillations in industry, American Elsevier Publ., New York, US, 1971.

[8] W. Krebs, P. Flohr, B. Prade, S. Hoffmann, Combust. Sci. Technol. 174 (2002) 99-128.

[9] R. Mongia, R. Dibble, J. Lovett, in: Proceedings ASME Turbo Expo 1998, 98-GT-304.

[10] J. G. Lee, K. Kim, D. A. Santavicca, Proc. Combust. Inst. 28 (2000) 415421.

[11] T. Sattelmayer, J. Eng. Gas Turb. Power 125 (2003) 11-19.

[12] J. H. Cho, T. C. Lieuwen, in: Proceedings ASME Turbo Expo 2003, GT2003-38089.

[13] J. H. Cho, T. Lieuwen, Combust. Flame 140 (2005) 116-129.

[14] S. H. Shreekrishna, T. Lieuwen, Combust. Theor. Model. 14 (2010) 681714.

[15] Y. M. Marzouk, A. F. Ghoniem, H. N. Najm, Proc. Combust. Inst. 28 (2000) 1859-1866.

[16] R. Lauvergne, F. N. Egolfopoulos, Proc. Combust. Inst. 28 (2000) 18411850.

[17] R. Sankaran, H. G. Im, Proc. Combust. Inst. 29 (2002) 77-84. 
[18] K. König, V. Bykov, U. Maas, Flow Turbul. Combust. 83 (2009) 105-129.

[19] A. L. Birbaud, S. Ducruix, D. Durox, S. Candel, Combust. Flame 154 (2008) $356-367$.

[20] R. Wu, S. Hemchandra, in: Proceedings 7th US National Combustion Meeting 2011, pp. 1285-1297.

[21] Y. Hardalupas, C. S. Panoutsos, A. M. K. P. Taylor, Exp. Fluids 49 (2010) 883-909.

[22] V. N. Nori, J. M. Seitzman, in: Proceedings 45th AIAA Aerospace Sciences Meeting 2007, AIAA 2007-466.

[23] J. Ballester, T. García-Armingol, Prog. Energ. Combust. Sci. 36 (2009) 375411.

[24] J. G. Lee, D. A. Santavicca, J. Propul. Power 19 (2003) 735-750.

[25] F. Guethe, D. Guyot, G. Singla, N. Noiray, B. Schuermans, Appl. Phys. B 107 (2012) 619-636.

[26] D. M. Kang, V. Fernandez, A. Ratner, F. E. C. Culick, Combust. Flame 156 (2009) 214-220.

[27] H. Schwarz, L. Zimmer, D. Durox, S. Candel, Exp. Fluids 49 (2010) 809821.

[28] M. S. Sweeney, S. Hochgreb, R. S. Barlow, Combust. Flame 158 (2011) 935-948. 
[29] H. Ax, P. Kutne, W. Meier, K. König, U. Maas, A. Class, M. Aigner, Appl. Phys. B 94 (2009) 705-714.

[30] H. Ax, Experimentelle Untersuchung magerer laminarer Niederdruckflammen mit periodisch variierender Gemischzusammensetzung, Ph.D. thesis, Universität Stuttgart, 2013.

[31] J. Kojima, Y. Ikeda, T. Nakajima, Combust. Flame 140 (2005) 34-45.

[32] W. L. Dimpfl, J. L. Kinsey, J. Quant. Spectrosc. Ra. 21 (1979) 233-241.

[33] C. J. Dasch, Appl. Optics 31 (1992) 1146-1152.

[34] V. Bergmann, W. Meier, D. Wolff, W. Stricker, Appl. Phys. B 66 (1998) 489-502.

[35] R. W. Bilger, Proc. Combust. Inst. 22 (1988) 475-488.

[36] P. Weigand, R. Lückerath, W. Meier, Documentation of Flat Premixed Laminar CH4/Air Standard Flames: Temperatures and Species Concentrations, http://www.dlr.de/vt/desktopdefault.aspx/tabid-3065/4632_read-6696/, last accessed 8/Oct./2015.

[37] S. Prucker, W. Meier, W. Stricker, Rev. Sci. Instrum. 65 (1994) 2908-2911.

[38] A. Levy, J. Sci. Instrum. 41 (1964) 449-453.

[39] R. S. Barlow, M. J. Dunn, M. S. Sweeney, S. Hochgreb, Combust. Flame 159 (2012) 2563-2575.

[40] T. M. Ombrello, C. D. Carter, in: Proceedings 49th AIAA Aerospace Sciences Meeting 2011, AIAA 2011-240. 
[41] C. K. Law, Combustion physics, Cambridge Univ. Press, Cambridge, GB, 2006.

[42] F. A. Williams, Prog. Energ. Combust. Sci. 26 (2000) 657-682.

[43] G. E. Andrews, D. Bradley, Combust. Flame 18 (1972) 133-153.

[44] E. W. Lemmon, R. T. Jacobsen, Int. J. Thermophys. 25 (2004) 21-69.

[45] D. F. Fairbanks, C. R. Wilke, Ind. Eng. Chem. 42 (1950) 471-475.

[46] J. O. Hirschfelder, C. F. Curtiss, R. B. Bird, Molecular Theory of Gases and Liquids, John Wiley \& Sons, New York, US, 3. edition, 1966.

[47] W. Jost, Diffusion - in Solids, Liquids, Gases, Academic Press Inc., New York, US, 3. edition, 1960. 